\title{
MATHEMATICAL MODELLING, SIMULATION ANALYSIS OF A PHOTOVOLTAIC THERMAL SYSTEM
}

\author{
Mohammad Taghi Hajibeigy ${ }^{1}$, Rashmi Walvekar ${ }^{1}$ and Aravind $\mathrm{CV}^{1^{*}}$
}

\begin{abstract}
Solar energy is one of the cleanest, environmentally friendly and abandoned available energy sources. While the photovoltaic (PV) module converts this free and available energy in the form of electrical energy, the efficiency of the PV module reduces as the temperature of the PV module rises above nominal value. The Photovoltaic Thermal (PVT) system removes the wasted thermal energy from the surface of the PV which is caused by the reflection of the sun's irradiance and stores it for the useful application, hence, maintain the electrical efficiency of the PV module. This paper analyses the heat response data collected from a PVT system, under normal conditions, with steady water acting as a coolant. Experimental and simulation values were compared and analyzed in this paper. The thermal response of the PVT system depends solely on the irradiation of sunlight. Therefore, the thermal energy output of the PVT system varies according to the solar irradiation. In this experiment, the PVT thermal response was measured via Thermocouple sensors mounted in each layer of the PVT system, which included solar panel, aluminum thermal plate, and heatsinks. A charge controller was connected to the output of the PV to regulate the charging process for a battery so that the electrical output can also be affected by the thermal response of the solar panel. The amount of solar irradiation was calculated based on the reading from the Pyranometer and the surface area of the PV. The setting of the Pyranometer and the thermocouples to measure the $\mathrm{PV}$ thermal value and the ambient temperature was set to ten seconds each, which was read using a data logger. The entire experiment is conducted in a constant condition such as constant ambient temperature and pressure to obtain fair data. Understanding the thermal transfer between each layer of the PVT system will help to increase the efficiency of the electrical and thermal output, from the study it was known that faster heat transfer maintains a steady temperature, this paper helps to design a PVT system with a better efficiency under a non-optimal condition.
\end{abstract}

\section{Keywords: Photovoltaic Thermal, Electrical Energy, Thermal Energy, Heat Transfer, Photovoltaic}

\section{INTRODUCTION}

Solar energy is one of the clean, renewable and sustainable sources of energy that can be harvested everywhere on the earth especially in places that have extended sunshine around the year like Malaysia. This source of energy can be harvested by Photovoltaic Thermal (PVT) which can contribute to the energy consumption of the household or industry both in electrical and thermal form. With regards to utilizing this combination of energy, the technology has been there for a while, but not much work has been done to improve it. PVT's must start to attract more interest in the solar energy sector due to increasing demands for renewable energy sources [1]. A PVT can harvest both electrical and thermal energy since the PV by itself alone only can retain up to $20 \%$ maximum and most of the energy around $70 \%$ is wasted via thermal [2]. The low efficiency of the PV can be further improved by harvesting the thermal portion of the Sun radiation on the PV system and collected such energy in a thermal tank for future usage. A suggested approach is to come up with mathematical modelling of the system, simulate using MATLAB/Simulink, analyze the gathered data, evaluate the efficiency as a means to transfer the thermal energy collected in a container under the PV and suggests the improved efficiency of the system and build the best model according to the results that been approached. This research is the specific mathematical modelling for the proposed system which can be accustomed based on the different types of materials and fluid as a coolant are used. In this paper, the concept of an energy balance was utilized to develop a mathematical model of a thermal system. Further, the obtained mathematical model could be simulated to better understand the contribution of each parameter to the overall effect of the system's efficiency.

\footnotetext{
This paper was recommended for publication in revised form by Regional Editor Ahmet Selim Dalkilic

${ }^{1}$ Faculty of innovation and technology, Taylor's University Lakeside, 47500 Subang Jaya, Selangor, Malaysia

${ }^{\star}$ E-mail address: aravindcv@leee.org

Orcid id: 0000-0003-0980-0998, 0000-0001-8283-1278, 0000-0002-2060-8748

Manuscript Received 25 July 2018, Accepted 26 February 2019
} 
Solar panels work perfectly only in certain weather conditions, but since the weather is always changing and the solar panels are used in different climates all over the world, most panels do not operate under ideal conditions. Understanding how solar panels react to these different conditions is essential for engineers to develop a solution accordingly [3]. With this knowledge, a design can be introduced to improve the efficiency of solar panels that operate in non-optimal conditions. This study was undertaken to employ water in the container as a coolant in the PVT system. PV cells when its strike with sunlight basically generates electricity, however, silicon PV cells tend to convert only a small part of the radiation to electricity while the rest results in heating of the solar panels. As a PVT system, there is a heat transfer of the cells to the thermal plate or tubes to the coolant underneath. The heating of the coolant reduces the temperature of the PV cells, therefore increasing their efficiency when the solar cells are exposed to a high temperature and radiation conditions. The hybrid PVT has a pump and storage tank, but in this paper, initially, only one part was shown and studied while the water is steady to analyze the behaviour of heat transfers. However, in the future experiment, nanofluid and circulating water using a pump will be investigated. In the solid medium of the PVT, heat transfer occurs merely by conduction, while in the fluid medium the heat transfer mode is a combination of convection and conduction. The flow is considered steady incompressible and the fluid is Newtonian [4].

In summary, the main reason for choosing a hybrid PVT system is due to its ability to provide both thermal energy and electrical energy. The hybrid PVT system will help to reduce the surface temperature of the solar panels in order to maintain the electrical efficiency of the PV. There are some overlapping with previous works to remove the heat from the PV surface. However, in the proposed system, heatsinks under the PV is utilized to absorb the heat from the surface of the PV and expel it into the fluid in the thermal container in order to transfer the thermal energy to the water in the water tank. The heatsinks are submerged in a fluid such as water or nanofluid in order to remove and absorb the temperature of the heatsinks. Lastly, the fluid in the thermal container is circulated in the heat exchanger submerged into the water in the thermal tank to elevate the temperature of the water in the thermal tank. The entire PVT system will help to maintain the electrical efficiency of the system, which can be concluded that as the thermal efficiency increases the electrical efficiency also increases.

Figure 1 exhibits the general idea of the PVT system principle. There are a number of unknowns in the experiment, therefore, few assumptions have to be made in order to conduct the experiment. The solar radiation read by the pyranometer is assumed to be the same as the radiation on the PV surface, due to the placement of the pyranometer the reading will be slightly different from the actual value this can be minimized by taking multiple reading in a different position to check how the radiation value changes with the position.

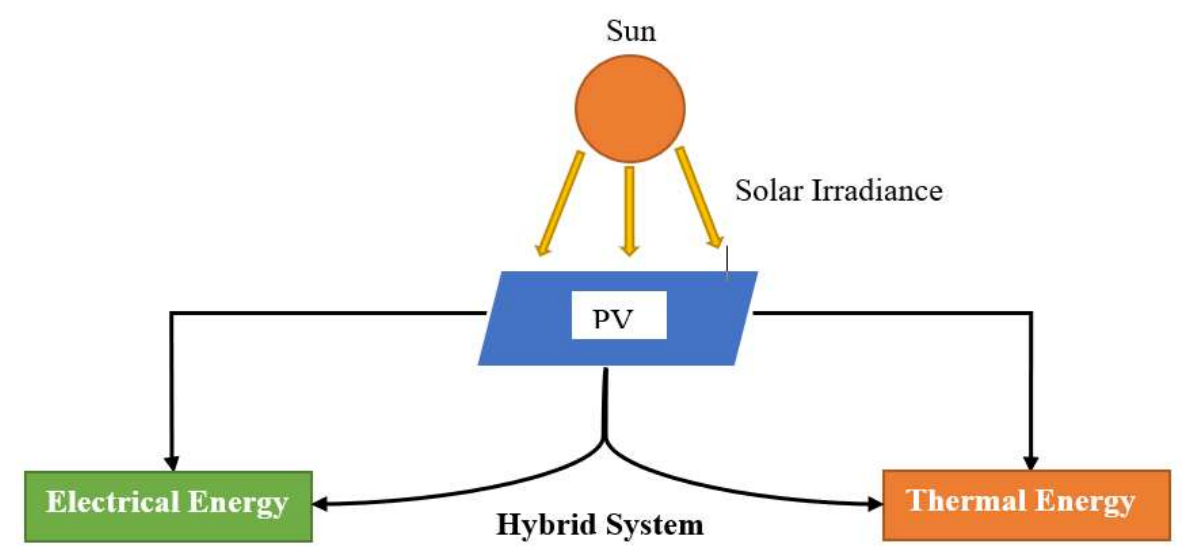

Figure 1. Overview of PVT systems

Nanofluid or suspensions of nanoparticles in liquids are defined as a mixture of a normal fluid such as water, oil, ethylene glycol, and molten salts) with a very small amount of solid metallic or metallic oxide nanoparticles or nanotubes [5].

\section{Advantage of Using CNT in PVT System}

- The integration of carbon nanotubes in solar and fuel cells had increased the energy conversion efficiency of these devices, which served as the future of renewable energy sources [6]. 
- Carbon nanotubes doped with metal hydrides showed a high hydrogen storage capacity of around $6 \%$ as a potential hydrogen storage medium.

- $\quad$ They showed high sensitivity toward the detection of environmental pollutants which were demonstrated by using carbon nanotubes-based sensors.

- Carbon nanotubes could be utilized as a reinforcement material in green Nanocomposites, which was advantageous in supplying the desired properties.

\section{MATHEMATICAL MODEL AND VALIDATION}

As a classic method of nonlinear dimensionality reduction, Locally Linear Embedding (LLE) is more attractive to researchers due to its ability to deal with large amounts of high dimensional data and its non-iterative way of finding the embedding. However, several problems in the LLE algorithm still remain open, such as its sensitivity to noise. In the PVT system, there will be too much noise due to constant changes in solar radiation every second [7].

Apart from LLE, an overall simulation of the heat exchanging process can be done using computational fluid dynamics (CFD). Using CFD to simulate the process has some drawbacks such as reasons discussed below $[8]$.

- errors may occur due to simple flow models or simplified boundary conditions

- possible uncertainties caused by too little computing values per cell and hence, therefore, resulting in interpolation errors

- computation time may extend for large models

- the costs may be much higher due to wrong consulting compared to experiments

The mathematical modelling developed in this research was based on the concept of an energy balance. The notion of energy balance equation states that in any given area, or location in a system, the heat in that area is equal to the heat leaving the area plus any heat that is stored in the material. One may say that

Thermal energy in $=$ Thermal energy out + Thermal energy stored

There exist major difficulties and challenges to create mathematical modelling for the thermal energy transferred from the surface of the PV all the way to the water in the water tank. To overcome these difficulties and challenges the modelling is divided into 6 different layers:

1. Heat transfer from the sun to the PV,

2. Heat transfer from the PV to the aluminum thermal plate,

3. Heat transfer from the aluminum thermal plate to the heatsinks,

4. Heat transfer from the heatsinks to the fluid,

5. Heat transfer from the fluid to the heat exchanger,

6. Heat transfer from the heat exchanger to the water.

The justification of the above method is to accurately consider the heat lost and related heat transfer factors to obtain the proper equation for each layer. The equations for each thermal transfer layer are shown in Equation 1 through Equation 37. The original achievements of the mathematical modelling of the system translated into simulation on how the temperature on the photovoltaic panel affects the thermal energy in each stage starting from the surface of the PV to the different layers of the hybrid collector all the way to the water in the tank. This will let the user simulate how much energy is being wasted and how much energy is turned into useful energy such as electrical energy and thermal energy to raise up the temperature of the water in the tank. Figure 2 shows the principles of the photovoltaic system.

All the steps of the simulation are illustrated in Figure 2. 


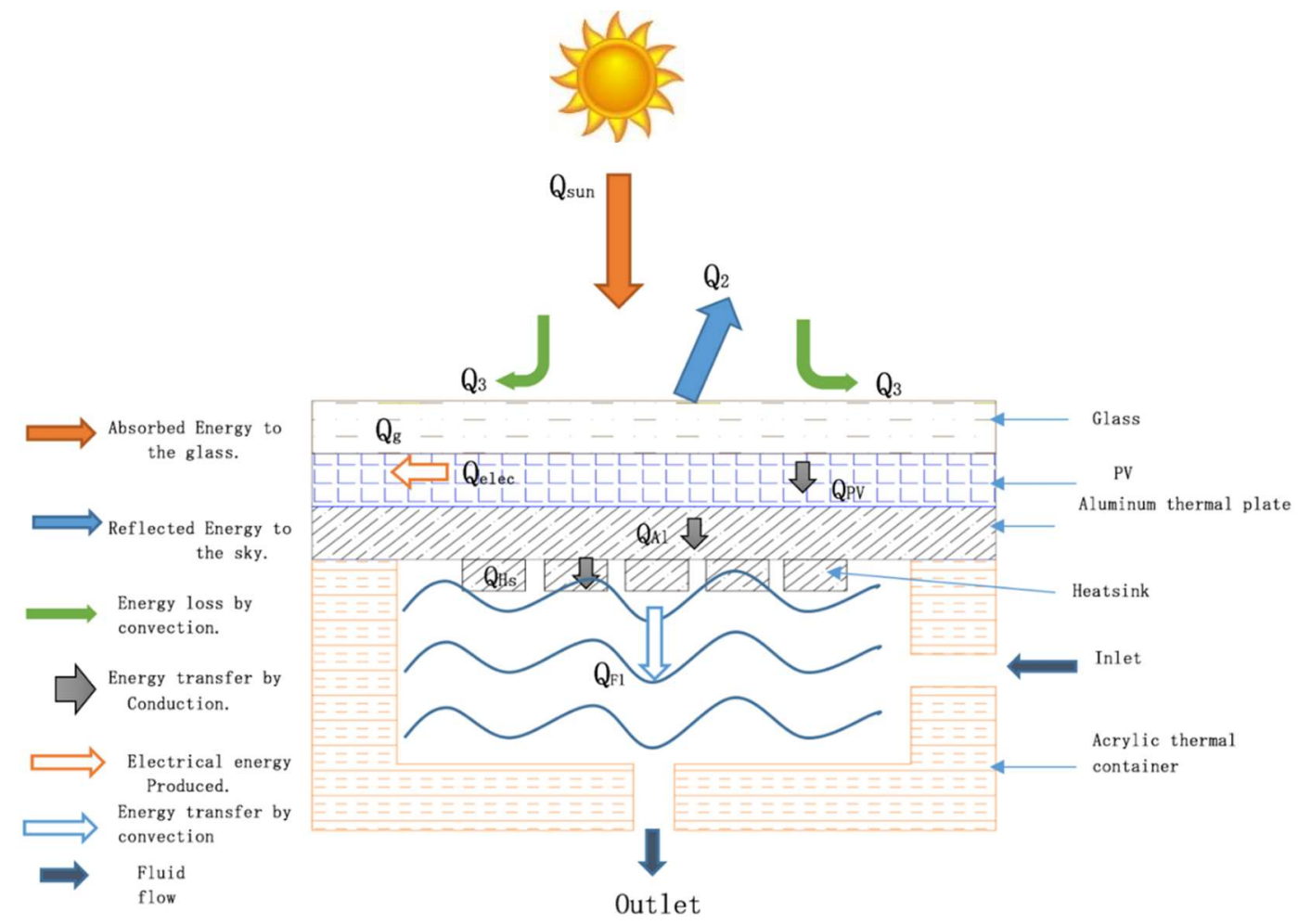

Figure 2. Principle of photovoltaic system

The overall project flow is shown in the flowchart in Figure 3.

\section{Heat Transfer from the Sun to the PV}

The net energy of the PV is as in Equation 1 [9].

$$
Q_{P V}=Q_{\text {Sun }}-\left(Q_{2}+Q_{3}+Q_{\text {elec }}\right)
$$

Sun energy projected to the surface of the PV is as in Equation 2.

$$
Q_{S u n}=\varepsilon_{g} \times \alpha_{P V} \times S \times A_{P V}
$$

Irradiation energy reflected to the sky is as in Equation 3.

$$
Q_{2}=\varepsilon_{g} \times \sigma \times A_{g} \times\left(T_{g}{ }^{4}-T_{a m b}{ }^{4}\right)
$$

Energy transfer by convection to the environment as in Equation 4.

$$
Q_{3}=\frac{\Delta T}{\frac{1}{\left(h_{a m b} \times A g\right)}}
$$

Electrical energy produced by the PV is as in Equation 5.

$$
Q_{\text {elec }}=\frac{Q_{\text {sun }} \times \eta_{r e f} \times e^{\left[\beta\left(T_{P V}-T_{r e f}\right)\right]}}{\alpha_{P V}}
$$

Overall net energy of the PV is as in Equation 6.

$$
Q_{P V}=\varepsilon g \times \alpha P V \times S \times A P V-\left[\varepsilon g \times \sigma \times A g \times\left(T_{g}^{4}-T_{a m b} b^{4}\right)+\frac{\Delta T}{\frac{1}{\left(h_{a m b \times A g}\right)}}+\frac{Q_{s u n} \times \eta_{r e f} \times e^{\left[\beta \times\left(T_{P V}-T_{r e f}\right)\right]}}{\alpha_{P V}}\right]
$$




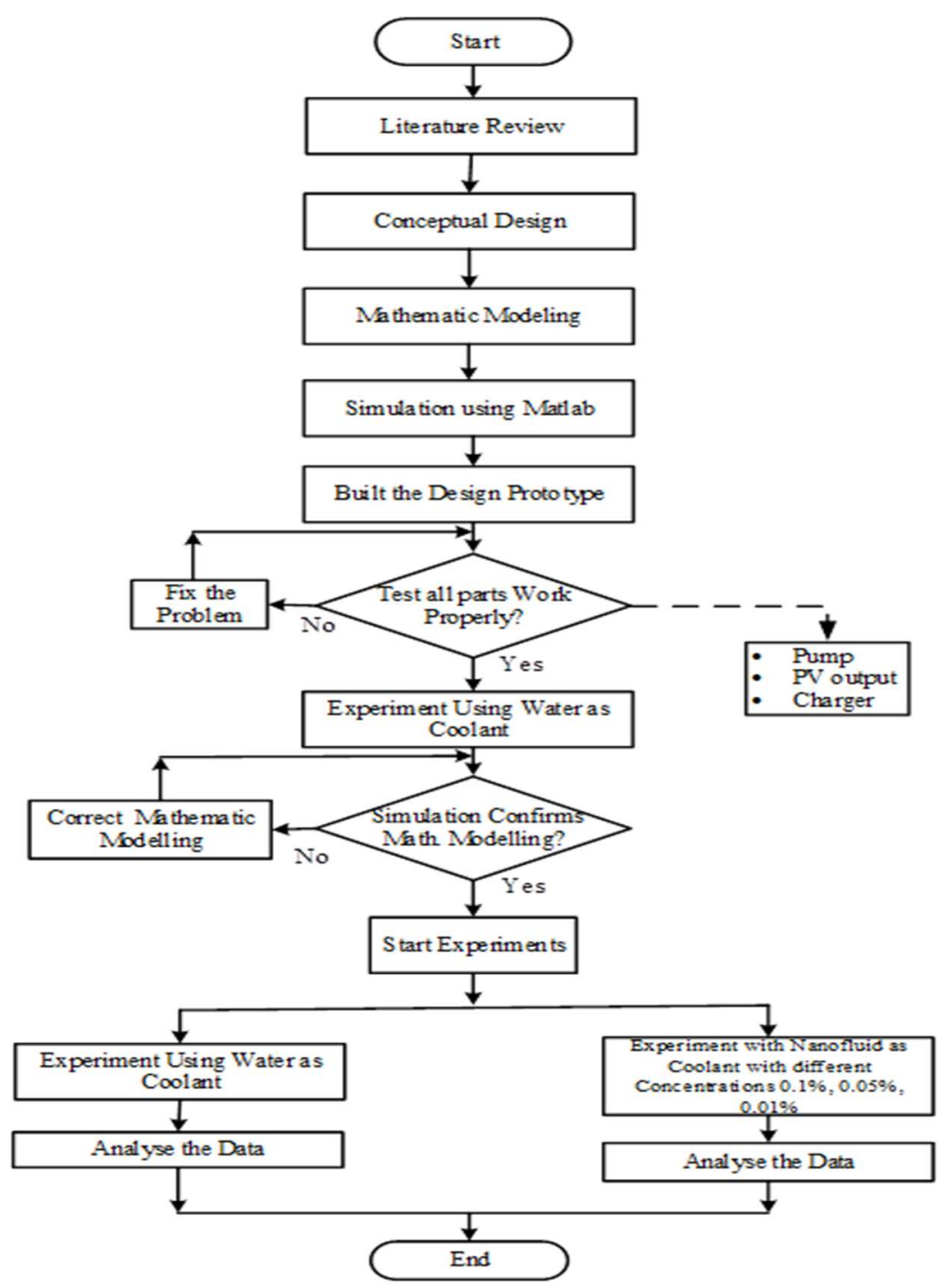

Figure 3. Flowchart of the overall work on the research

The heat transfer occurs from the sun to the different layers of the hybrid collector. Path to be followed for each layer has been determined.

\section{Heat Transfer from the PV to the Aluminum Thermal Plate}

Figure 4 shows the connection of the PV with the aluminum thermal plate through thermal glue.

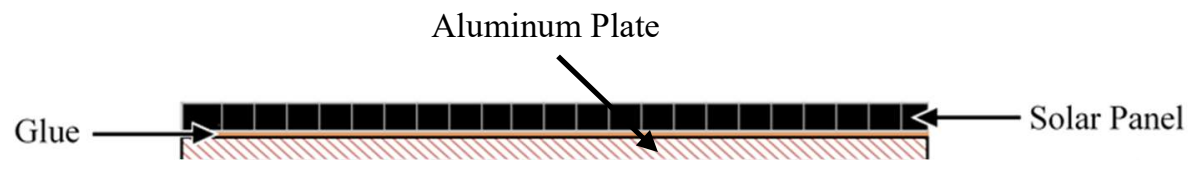

Figure 4. Representation of PV, aluminum plate and glue

In here, there are two heat losses by conduction in the glue and by convection due to the air gaps. However, these losses can be negligible, but can be calculated as shown below [10], [11].

The net energy of the aluminum thermal plate as is as in Equation 7.

$$
Q_{A l}=Q_{P V}-\left(Q_{R A l}+Q_{c n V_{-} A l}+Q_{c n d_{-} g l}\right)
$$

Resistive transfer energy of the aluminum thermal plate is as in Equation 8.

$$
Q_{R A l}=\frac{\Delta T}{R_{A l}}
$$


The thermal resistance of the aluminum thermal plate as in Equation 9.

$$
R_{A l}=\frac{b_{A l}}{K_{A l} \times A_{A l}}
$$

Energy of resistance of the aluminum thermal plate is as in Equation 10.

$$
Q_{R A l}=\frac{\Delta T \times K_{A l} \times A_{A l}}{b_{A l}}
$$

Convective heat transfer effected by the wind speed is as in Equation 11.

$$
h=2.56 \times W_{V}+8.55
$$

The heat loss by convection due to the uniform aluminum thermal plate with PV is as in Equation 12.

$$
Q_{c n v_{-} A l}=h_{a m b} \times A_{A l} \times\left(T_{A l}-T_{a m b}\right)
$$

The heat loss by convection through the glue in between the PV and the aluminum thermal plate is as in Equation 13.

$$
Q_{c n d \_g l}=K_{g l} \times \frac{A_{g l}}{b_{g l}} \times\left(T_{g l}-T_{A l}\right)
$$

Overall of the net energy of the aluminum thermal plate is as in Equation 14.

$$
\begin{gathered}
Q_{A I}=\varepsilon_{g} \times \alpha P V \times S \times A_{P V}-\left[\varepsilon_{g} \times \sigma \times A_{g} \times\left(T_{g}^{4}-T_{a m b} 4\right)+\frac{\Delta T}{\frac{1}{\left(h_{a m b} \times A_{g}\right)}}+\frac{Q_{s u n} \times \eta_{r e f} \times e^{\left[\beta\left(T_{P V}-T_{r e f}\right)\right]}}{\alpha_{P V}}\right. \\
{\left[\frac{\Delta T \times K_{A l} \times A_{A l}}{b_{A l}}+h_{a m b} \times A_{A l} \times\left(T_{A l}-T_{a m b}\right)+K_{g l} \times \frac{A_{g l}}{b_{g l}} \times\left(T_{g l}-T_{A I}\right)\right]}
\end{gathered}
$$

\section{Heat Transfer from the Aluminum Thermal Plate to the Heatsinks}

Figure 5 shows the heatsinks used in the experiment. It was used to extract the heat from the top layer aluminum plate and transferred to the coolant which is submerged into it. The heatsinks are made of aluminum metal that is anti-rust with good heat transfer capability where thermal energy is dissipated away from the device, thus allowing regulation of the device's temperature at optimal levels [12].

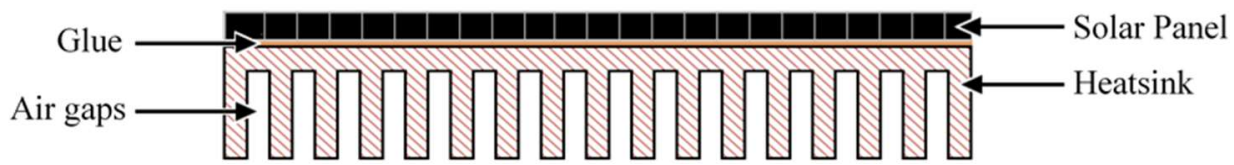

Figure 5. Representation of aluminum plate and heatsinks

The net energy transfer from the aluminum plate to the heatsinks is as in Equation 15.

$$
Q_{H S}=Q_{A l}-\left(Q_{R H S}+Q_{c n v_{-} \text {cont_air }}\right)
$$

Resistive transfer energy of the heatsinks is as in Equation 16.

$$
Q_{R H S}=\frac{\Delta T \times K_{H S} \times A_{H S}}{L}
$$

Heat loss to the air gap from the aluminum thermal plate and the heatsinks is as in Equation 17.

$$
Q_{c n v_{-} c o n t \_a i r}=h_{c o n t \_a i r} \times A_{A I} \times\left(T_{A I}-T_{\text {cont_air }}\right)
$$

Overall net energy transfer from the aluminum plate to the heatsinks is as in Equation 18. 


$$
\begin{gathered}
Q_{H S}=\varepsilon_{g} \times \alpha P V \times S \times A P V-\left[\varepsilon_{g} \times \sigma \times A_{g} \times\left(T_{g}^{4}-T_{a m b}{ }^{4}\right)+\frac{\Delta T}{\frac{1}{\left(h_{a m b} \times A g\right)}}+\frac{\left.Q_{s u n} \times \eta_{r e f} \times e^{\left[\beta\left(T_{P V}-T_{r e f}\right)\right.}\right]}{\alpha_{P V}}\right]- \\
{\left[\frac{\Delta T \times K_{A l} \times A_{A l}}{b_{A l}}+h_{a m b} \times A_{A l} \times\left(T_{A l}-T_{a m b}\right)+K_{g l} \times \frac{A_{g l}}{b_{g l}} \times\left(T_{g l}-T_{A l}\right)\right]-\left[\frac{\Delta T \times K_{H S} \times A_{H S}}{L}+\right.} \\
\left.h_{\text {cont_air }} \times A_{A l} \times\left(T_{A l}-T_{\text {cont_air }}\right)\right]
\end{gathered}
$$

\section{Heat Transfer from the Heatsinks to the Fluid}

The net energy transfer from the heatsinks to fluid is as in Equation 19 [13].

$$
Q_{F I}=Q_{H S}-\left(Q_{c n V_{-} \text {cont_air }}+Q_{c n d_{\_} \text {cont }}\right)
$$

Heat loss from the heatsinks to the air of the container is as in Equation 20.

$$
Q_{c n n_{-} \text {cont_air }}=h_{\text {cont_air }} \times A_{H S} \times\left(T_{H S}-T_{\text {cont_air }}\right)
$$
Equation 21.

Heat loss by conduction throw the thermal container to the ambient outside the thermal container is as in

$$
Q_{c n d} \text { cont }=K_{a r c} \times A \times\left(T_{a r c}-T_{a m b}\right)
$$

This loss can be negligible since container is insulated with a high reflector to $97 \%$, heat loss will be only $3 \%$.

Overall net energy transfer from the heatsinks to fluid is as in Equation 22.

$$
\begin{aligned}
& Q_{F I}=\varepsilon g \times \alpha P V \times S \times A P V-\left[\varepsilon g \times \sigma \times A_{g} \times\left(T_{g}^{4}-T_{a m b}\right)+\frac{\Delta T}{\frac{1}{\left(h_{a m b} \times A_{g}\right)}}+\frac{Q_{s u n} \times \eta_{r e f} \times e^{\left[\beta\left(T_{P V}-T_{r e f}\right)\right]}}{\alpha_{P V}}\right]- \\
& {\left[\frac{\Delta T \times K_{A l} \times A_{A l}}{b_{A l}}+h_{a m b} \times A_{A l} \times\left(T_{A l}-T_{a m b}\right)+K_{g l} \times \frac{A_{g l}}{b_{g l}} \times\left(T_{g l}-T_{A l}\right)\right]-\left[\frac{\Delta T \times K_{H S} \times A_{H S}}{L}+h_{\text {cont_air }} \times A_{A l}\right.} \\
& \left.\times\left(T_{A l}-T_{\text {cont_air }}\right)\right]-\left[h_{\text {cont_air }} \times A_{H S}\left(T_{H S}-T_{\text {cont_air }}\right)+K_{\text {arc }} \times A_{\text {arc }} \times\left(T_{\text {arc }}-T_{a m b}\right)\right]
\end{aligned}
$$

\section{Heat Transfer from the Fluid to the Heat Exchanger}

Figure 6 shows the orientation of the copper pipe used as a heat exchanger [14].

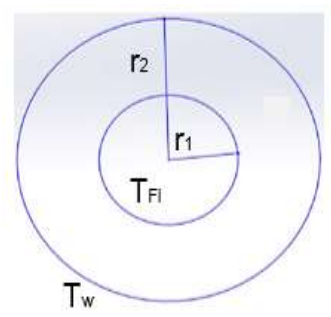

Figure 6. The diameters of the heat exchanger pipe

Energy of Heat exchanger $\left(Q_{e x}\right)$ is as in Equation 23.

$$
Q_{e x}=Q_{F l}-\frac{\Delta T}{Q_{c n d_{\_} p i}+Q_{c o n v_{-} p i}+Q_{\text {conv_pi_in }}}
$$

Heat loss by convection in the pipe material is as in Equation 24. 


$$
Q_{c n d_{-} p i}=\frac{2 \pi \times L \times k_{p_{-} m i d}}{\ln \left(\frac{r_{1}}{r_{2}}\right)} \times\left(T_{F L}-T_{a m b}\right)
$$

Heat loss by conduction in the pipe material is as in Equation 25.

$$
Q_{c n v_{-} p i}=h_{a m b} \times 2 \pi \times r_{2} \times L \times\left(T_{F l}-T_{W}\right)
$$

Heat loss by convection of the pipe's outside layer is as in Equation 26.

$$
Q_{c o n V_{-} p i_{-} i n}=h_{F I} \times 2 \pi \times r_{1} \times L \times\left(T_{F L}-T_{W}\right)
$$

Overall Energy of Heat exchanger $\left(\mathrm{Q}_{\mathrm{ex}}\right)$ is as in Equation 27.

$$
\begin{aligned}
& Q_{e X}=\varepsilon_{g} \times \alpha_{P V} \times S \times A_{P V}-\left[\varepsilon_{g} \times \sigma_{A g} \times\left(T_{g}^{4}-T_{a m b^{4}}\right)+\frac{\Delta T}{\frac{1}{\left(h_{a m b} \times A_{g}\right)}}+\frac{Q_{s u n} \times \eta_{r e f} \times e^{\left[\beta\left(T_{P V}-T_{r e f}\right)\right]}}{\alpha_{P V}}\right]- \\
& {\left[\frac{\Delta T \times K_{A l} \times A_{A l}}{b_{A l}}+h_{a m b} \times A_{A l} \times\left(T_{A l}-T_{a m b}\right)+K_{g l} \times \frac{A_{g l}}{b g l} \times\left(T_{g l}-T_{A l}\right)\right]-\left[\frac{\Delta T \times K_{H S} \times A_{H S}}{L}+h_{\text {cont_air }} \times A_{A l} \times\right.} \\
& \left.\left(T_{A I}-T_{\text {cont_air }}\right)\right]-\left[h_{\text {cont_air }} \times A_{H S} \times\left(T_{H S}-T_{\text {cont_air }}\right)+K_{a r c} \times A \times\left(T_{\text {arc }}-T_{a m b}\right)\right]-\left[\frac{2 \pi \times L \times K_{\text {Pi_mid }}}{\ln \left(\frac{r_{1}}{r_{2}}\right)} \times\right. \\
& \left.\left(T_{F 1}-T_{a m b}\right)+h_{a m b} \times 2 \pi \times r_{2}\left(T_{F 1}-T_{a m b}\right)+\left(h_{F 1} \times 2 \pi \times r_{1} \times L \times\left(T_{F 1}-T_{W}\right)\right)\right]
\end{aligned}
$$

To complete the calculation, we need to find $\mathrm{h}_{F}$. The most important step in heat convection calculations is the determination of the appropriate heat transfer coefficient. The higher the fluid velocity is, the higher the heat transfer coefficient is as in Equation 28.

$$
h_{F l}=\frac{N u \times K}{D}
$$

Reynolds number is as in Equation 29.

$$
R e=\frac{\rho \times F l_{v} \times D}{\mu}
$$

When the value of the Reynolds number for pipe flow is less than 2100, the flow is streamlined and regular and is called laminar. Above $\mathrm{Re}=2100$, the flow is highly chaotic and irregular and is said to be turbulent.

The following are the conditions for the Reynolds number:

Laminar-when $\operatorname{Re}<2300$

Transient-When $\operatorname{Re} 2300<\operatorname{Re}<4000$

Turbulent-When $\operatorname{Re}>4000$

The Prandtl number is defined is as in Equation 30.

$$
\operatorname{Pr}=\frac{\mu \times C p}{K}
$$

For Laminar Flow in tubes, the following correlation applied is as in Equation 31.

$$
N u=3.66+\frac{0.0668 \times\left(\frac{D}{L}\right) \operatorname{Re} \times P r}{1+0.004 \times\left[\left(\frac{D}{L}\right) \operatorname{Re} \times P r\right]^{2 / 3}}
$$

For Turbulent Flow in tubes, is as in Equation 32.

$$
N u=0.023 \times R e^{0.8} p^{n}
$$


where $n=0.4$ for heating and $n=0.3$ for cooling.

\section{Heat Transfer from the Heat Exchanger to the Water}

Heat transfer from the heat exchanger is as in Equation 33 [15], [16].

$$
\frac{(T 1-T 2)}{Q_{c n d_{-} C p}+Q_{c o n v_{-} C p}+Q_{\text {conv_Cp_in }}}
$$

Energy transfer from the exchanger to the water in the tank is as in Equation 34.

$$
Q_{c n d \_C p}=\frac{2 \pi \times L \times K_{C p \_m i d}}{\ln \left(\frac{r_{1}}{r_{2}}\right)}\left(T_{F l}-T_{W}\right)
$$

Heat loss by conduction by copper pipe material is as in Equation 35 .

$$
Q_{c o n V_{-} C p}=h_{W} \times 2 \pi \times r_{2} \times L \times\left(T_{F l}-T_{W}\right)
$$

Heat loss by convection by the outside layer of the copper pipe is as in Equation 36 and Equation 37.

$$
\begin{gathered}
Q_{c o n{ }_{-} C p_{-} i n}=h_{F l} \times 2 \pi \times r_{1} \times L \times\left(T_{F l}-T_{W}\right) \\
Q_{W}=\left[\frac{2 \pi \times L \times K_{C p_{-} m i d}}{\ln \left(\frac{r_{1}}{r_{2}}\right)}+\left(h_{W} \times 2 \pi \times r_{2} \times L\right)+\left(h_{F l} \times 2 \pi \times r_{1} \times L\right)\right] \times\left(T_{F}-T_{W}\right)
\end{gathered}
$$

Figure 7 shows a diagram of the experimental setup.

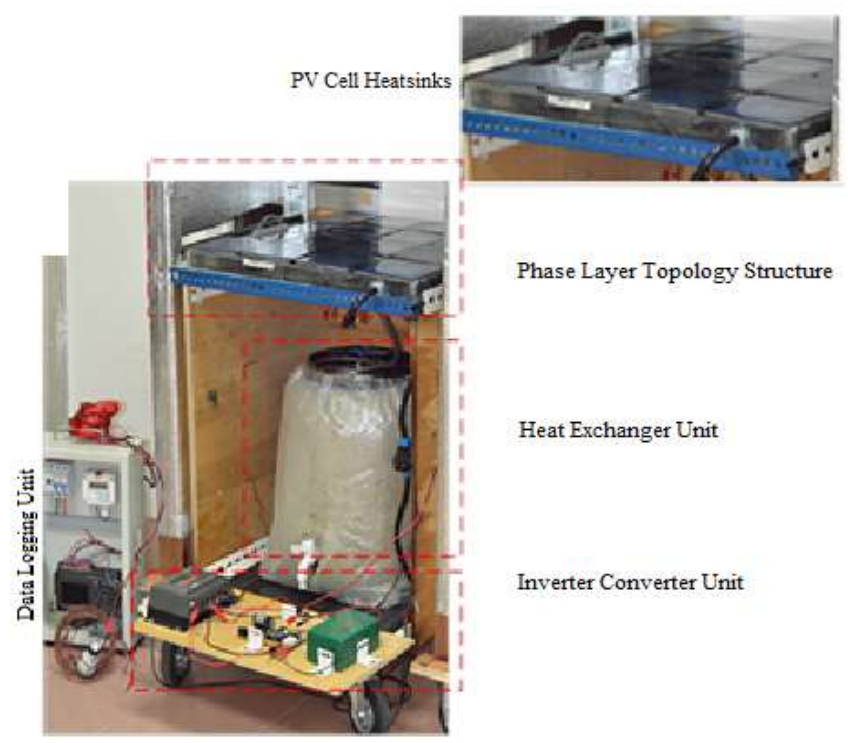

Figure 7. Proposed system with data logger and charge controller

\section{EXPERIMENTAL VERIFICATION}

This experiment investigates the thermal energy transfer in the PVT system to identify the system behaviour according to solar irradiation since the heat transfer of the system layers, in this case, depending solely on the irradiation. Also, the solar panel temperature is important to know which affects the electrical output power and leads to reduce efficiency [8]. However, water was employed in the thermal container without any circulation as a start in this experiment. Later, water was circulated via a pump through the system from the thermal container where the heatsinks were submerged to the heat exchanger which was located in the water tank. The intensity of the light was measured by a pyranometer and the thermal temperature of each layer and the water in the tank by thermocouples. These values were recorded by a data logger for a specific interval. 
The pyranometer is a device that was used to measure solar irradiance on a flat surface which can measure the solar radiation flux density $\left(\mathrm{W} / \mathrm{m}^{2}\right)$. The pyranometer is directly connected to the data logger to accurately track the solar irradiation since the output is in terms of voltage. There are some drawbacks in the pyranometer settings which in the experiment, only one pyranometer was used. Therefore, there will be a slight difference compared to the actual value. Last but not least the main reason for using the particular pyranometer is due to its accuracy and ease of calibration. This will help to maintain fair data throughout the experimentation process with reliable data.

The data logger is an electronic device which records data over a set frequent time in relation to a sensor. The frequency of capturing data can be set from 1 second to the minutes' range. The duration of the capturing data can be set as the user desired from minutes to hours. In this research, the data logger was set to capture the data every 2 seconds for 3 hours. The data obtained was saved in a Universal Serial Bus (USB) drive which was placed in the data logger and later transferred to the computer for analysis. The 2-second interval was chosen due to the specification of the data logger for the temperature. The data logger which was used during this research has a minimum interval of 2 seconds for the data logger when conducting the experiment both the data logger has to record the data simultaneously to obtain proper data.

The thermocouple is a sensor that was used to measure the ambient temperature in conjunction with recording the irradiance of the Sun at the same time. These data, solar irradiance and ambient temperature were saved in the same thumb drive and later transferred to a computer for analysis. The reason behind choosing thermocouple over other sensors such as Temperature Resistance Device (TRD), is its high accuracy, speed, and it is easier to integrate with a data logger since its output is the voltage where the output of most of the other sensors is resistance. Table 1 shows the critical design parameters of the PVT system. Few of the parameters such as ambient temperature, solar radiation and air velocity were assumed. The fluctuation of the ambient temperature compared to the initial temperature of the lab $23{ }^{\circ} \mathrm{C}$ was minimal two, which has a low sensitivity to the overall result of the experiments. The solar radiant read by the pyranometer is assumed to be the same as on the PV surface since they are placed next to each other on the same level. The air velocity was assumed to be $0 \mathrm{~m} / \mathrm{s}$ since the experiments were conducted in a lab. The rationale behind these assumptions is that minimal differences have an almost insignificant effect on the overall result.

Table 1. Design parameters

\begin{tabular}{|c|c|}
\hline Parameter & Value \\
\hline Glass transmissivity & 0.9 \\
\hline Cell material absorptivity & 0.9 \\
\hline Tedlar absorptivity & 0.5 \\
\hline Packing factor & 0.86 \\
\hline Dimension of each cell & $16 \mathrm{~cm} \times 15 \mathrm{~cm} \times 0.2 \mathrm{~cm}$ (Length $\times$ Width $\times$ Height) \\
\hline Power and voltage of each cell & Power $=3 \mathrm{~W}$, Voltage $=12 \mathrm{~V}$ \\
\hline Thermal Collector Box & $65 \mathrm{~cm} \mathrm{X} 61 \mathrm{~cm} \mathrm{X} 4 \mathrm{~cm}$ (Length X Width X Height) \\
\hline Solar irradiation & 200 to $1000 \mathrm{~W} / \mathrm{m}^{2}$ \\
\hline Ambient temperature & $23{ }^{\circ} \mathrm{C}$ \\
\hline Air Velocity & $0.0 \mathrm{~m} / \mathrm{s}$ (Experiments were conducted in the lab) \\
\hline
\end{tabular}

For the simulation of this research, MATLAB software was employed for further analyzing the data obtained, to calculate the heat transfer of the PVT and the efficiency in relation to the solar irradiance and ambient temperature. However, other programs could be utilized as well for data processing. In this particular research, MATLAB was used because of its capabilities for simulation, optimization, statistics, data analysis, and a large user community with lots of free code and knowledge sharing. 


\section{RESULTS AND DISCUSSION}

Different sensors such as thermocouples and pyranometer were used to collect data via a data logger. Thermocouples were utilized to collect the temperature of ambient, PV, aluminum plate, heatsinks, water in a thermal container, and water in the tank while a pyranometer was used to collect the solar irradiance. MATLAB program was utilized for further analyzing the obtained data. The data obtained on solar irradiance further was used by the simulation program to ensure the correctness of the simulation program.

The data that has been taken from the temperature sensors and the pyranometer, later on, be used by MATLAB to be further analyzed, the MATLAB software has been chosen for this simulation is due to its userfriendly interface compared to excel or other software such as MATLAB allows all the equations at each stage to be easily inputted and edited without interfering with different stages. Figure 8 below are the outputs of this experiment and the simulation. Figure 8 shows the solar radiation used in the experimental portion of the research. The Figures below depict the experimental and simulation results. Figure 8 shows the solar radiation used in the experimental portion of the research.

Heat is characterized as the type of energy that is exchanged between two systems by the ideals of a temperature contrast. Figure 9 shows the thermal energy simulation and experimental, which transferred by solar radiation from the sun to the PV. The thermal energy is rising in some points which indicates the PV is gaining thermal energy and reaches around $220 \mathrm{~W}$.

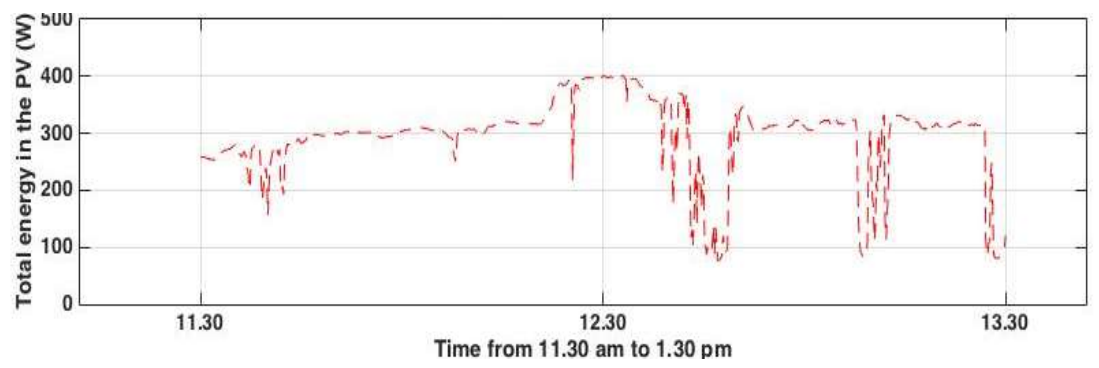

Figure 8. Solar radiation
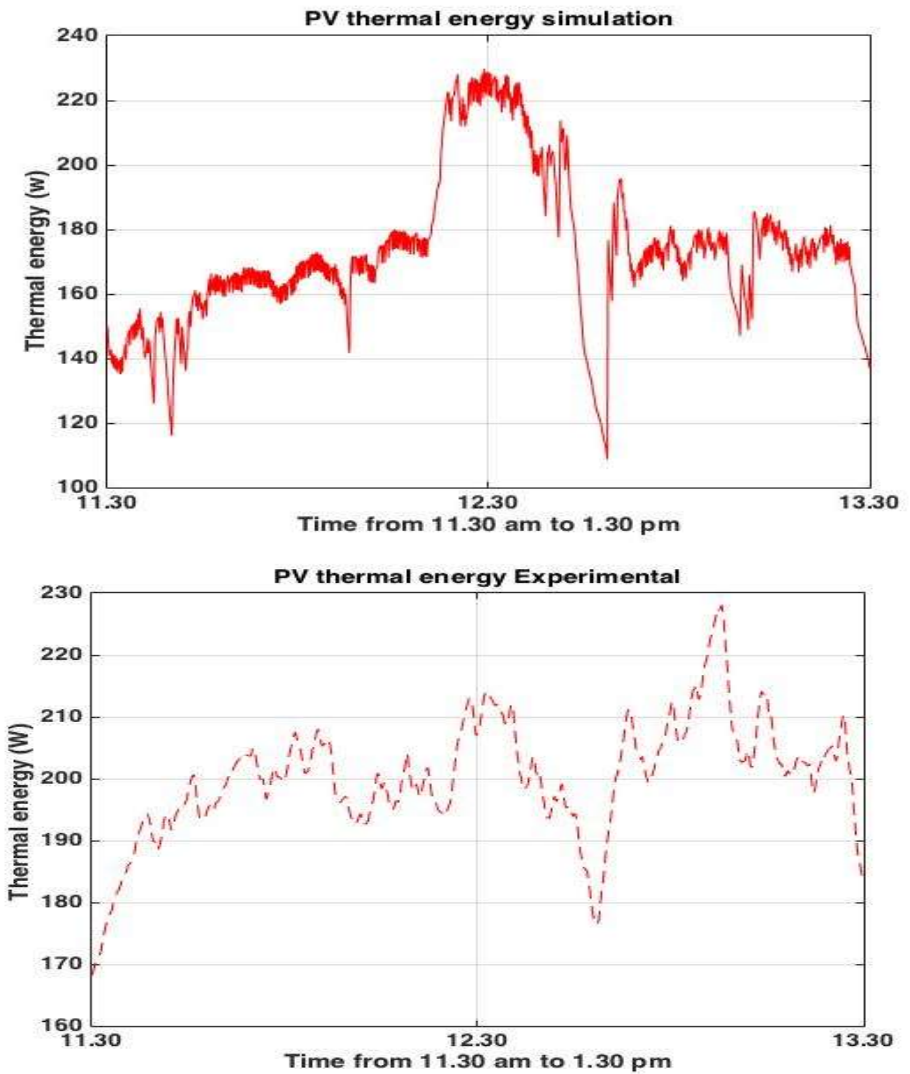

Figure 9. Simulation and experimental of thermal energy 
Figure 10 shows a comparison between the experimental and simulation analysis of each layer's temperature in the PVT system. The layers in sequence solar panel, aluminum thermal plate, heatsinks, and water in the container. Figure 10 shows that the aluminum, heatsinks, and water container temperature are very much alike, hence confirming the mathematical modelling of the system. There are slightly different which requires further enhancement of the mathematical model. The slight peak on the heatsinks and the water is due to the relationship correlating the amount of radiation and the temperature of the heatsinks and the water at a given time. Figure 10 indicates that the behaviour of the temperature in each layer depending solely on solar radiation, as shown in Figure 1. However, the surface of the thermal aluminum plate is bent and deform because of the heat generated while welding the heatsinks so it's not symmetry with the solar panel which leads to some heat loss also the thermal glue in between which has $2 \%$ loss and that explain the gap in between the thermal aluminum plate and the PV panel.
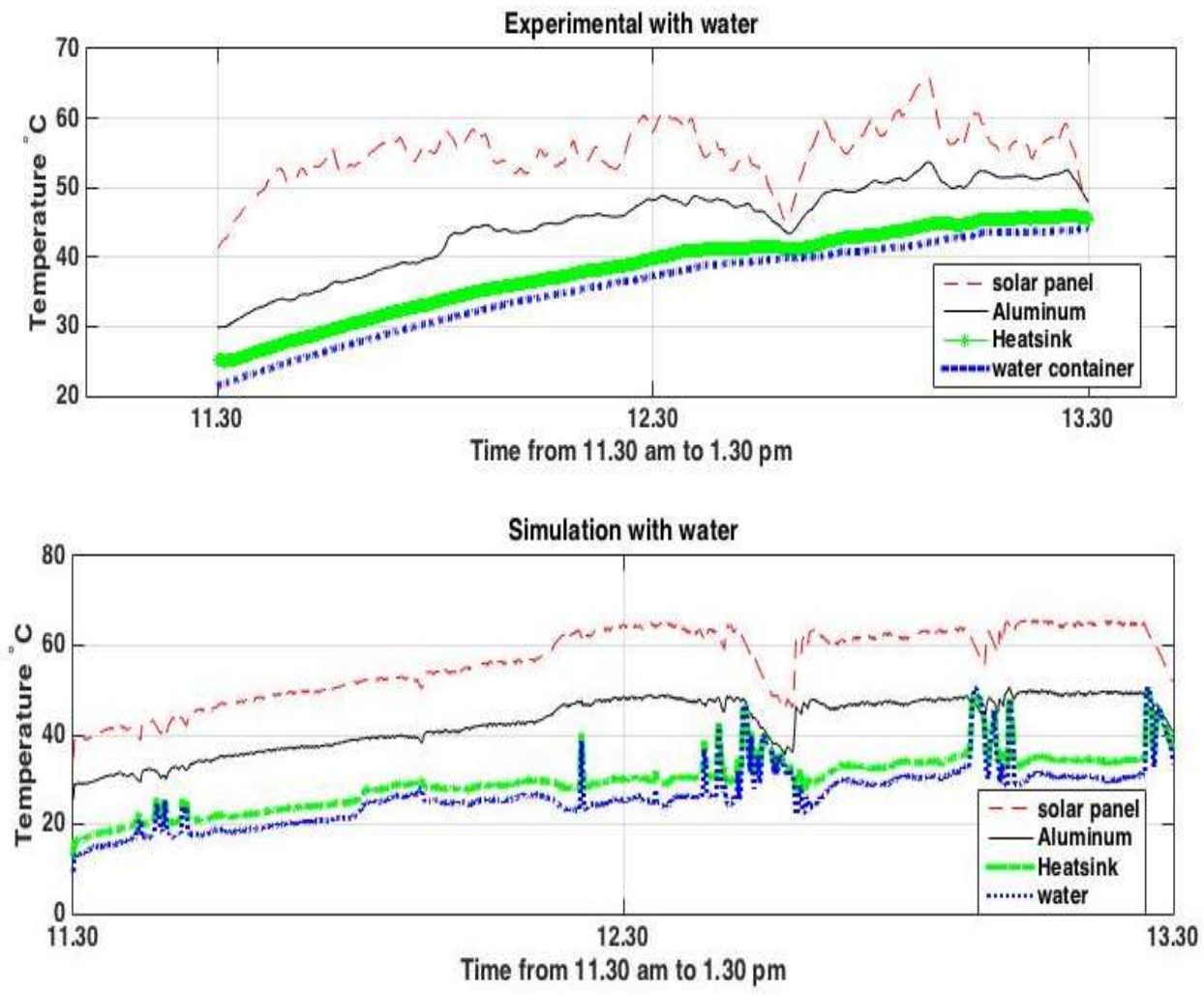

Figure 10. Simulation and experimental of PVT layer heat transfer

Noticing a drop of the thermal energy between 12 noon to $13 \mathrm{pm}$, that's can be explained as the panel cooling down by losing heat to the outer layer of the PVT system, which is the thermal plate. Moreover, the thermal plate reached a maximum energy of $300 \mathrm{~W}$ result of the interaction between the PV and the thermal plate. Spontaneously, heat flows from a hotter body to a colder one. This heat transfer process between the PV panel and the thermal plate called conduction since there are two plates attached to each other. The drop in some points can be explained that the thermal energy is transferred out of the plate to the heatsinks under the plate.

The graph shows the different energy level for each layer, the thermal energy from the photovoltaic will be transferred to the water while traveling between each layer it can be seen that there will be a certain amount of energy lost due to convection and conduction between layers as shown in Figure 11. The total heat loss of the system can be calculated by comparing the thermal energy of the PV to the thermal energy of the water which is illustrated in Figure 11. From the calculation below, 16.2\% of the thermal energy of the PV has been captured as useful energy. The mathematical modelling and the simulation of the system can show where the improvement of the system in terms of thermal and electrical efficiency is needed.

$$
\frac{68-57}{68} \times 100=16.2 \%
$$


In general, the electrical efficiency of $\mathrm{PV}$ will drop by $0.4 \%$ per ${ }^{\circ} \mathrm{C}$ when the temperature of the $\mathrm{PV}$ is above $27^{\circ} \mathrm{C}$. According to an article published by civic solar [17], [18], heat can reduce electrical output efficiency by $10-25 \%$, thereby removing the thermal energy of the system the electrical efficiency can be improved. It can be inferred that by capturing more thermal energy, the electrical efficiency of the system can be improved.

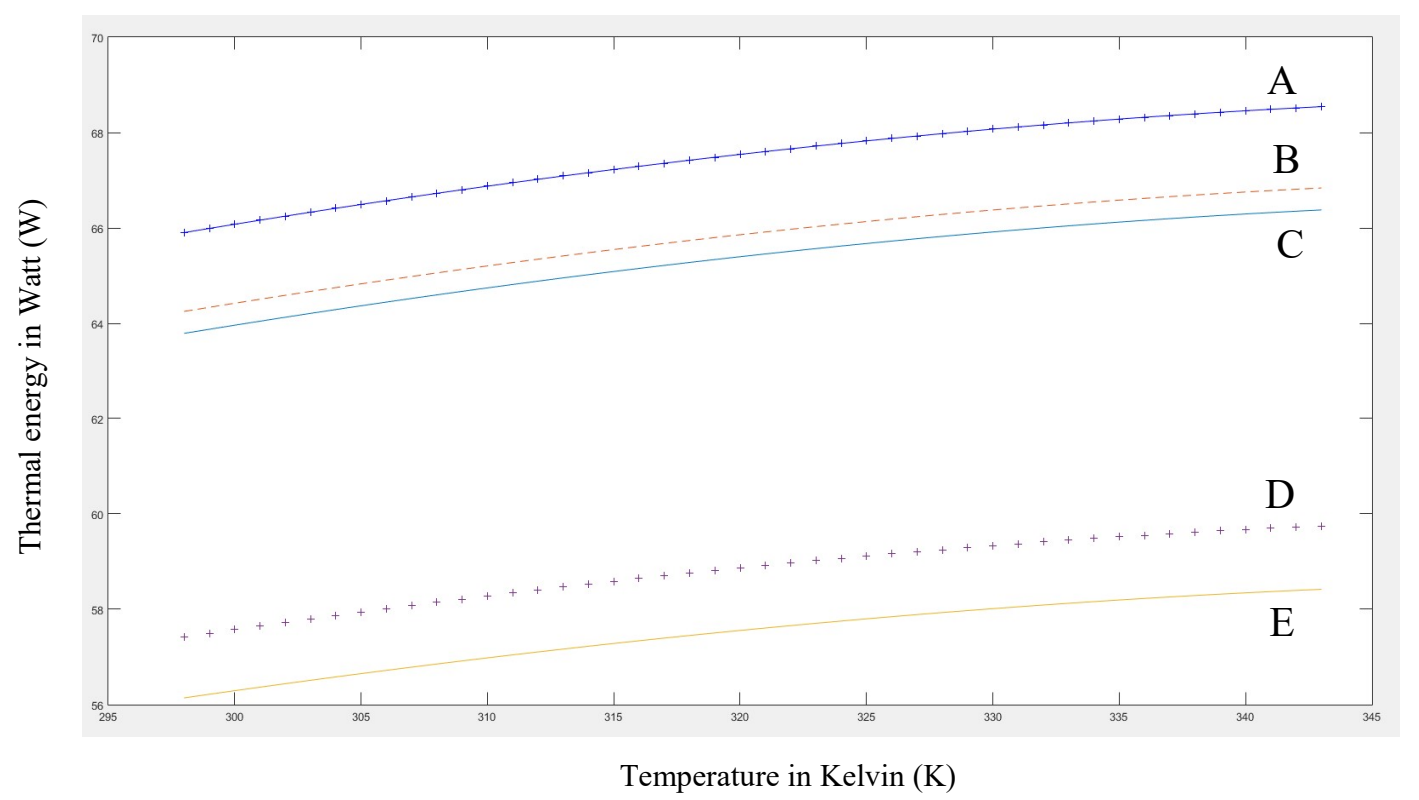

Figure 11. Thermal energy simulation of the proposed PVT system

- A: Thermal energy of the photovoltaic module

- B: Thermal energy of the heatsinks

- C: Thermal energy of coolant

- D: Thermal energy of heat exchanger

- $\mathrm{E}$ : Thermal energy of water in the water tank

\section{CONCLUSION}

The sensible and viable use of solar energy is a critical way which can manage the worldwide vitality crisis at present. The PV cell converts solar radiation to electrical energy with no structure for mechanical thermal interlink. Therefore, the study on enhancing the productivity of the solar panel is exceptionally essential. This paper showed the thermal response of the PVT system layers and how much the solar panel can absorb heat when the temperature rises. Finding a way to remove the thermal energy transfer faster on each layer can help to improve the electrical efficiency of the PV and its thermal energy generated by the solar radiation. Hence, fast heat transfer among the layers of the PVT system can maintain a steady lower temperature on the PV, which improves the PV module's electrical efficiency. With this knowledge, a design can be produced to improve the efficiency of solar panels that operate in non-optimal conditions. However, this study will be continued to employ a nanofluid to improve furthermore the heat transfer in the PVT system. Last but not least the mathematical modelling can be further improved by smoothing out the simulated graph especially on the heatsink and the water, to make it identical to the experimented results. This implementation will help to further reduce the errors in the simulation. Apart from that different amounts of nanofluid concentration and different types of nanofluid can be studied to get the best combinations to cool down the PV module.

\section{NOMENCLATURE}

$\begin{array}{ll}\Delta \mathrm{T} & \text { Temperature difference, } \mathrm{K} \\ \mathrm{A} & \text { Surface area, } \mathrm{m}^{2} \\ \mathrm{~b} & \text { Thickness, } \mathrm{m} \\ \mathrm{Cp} & \text { The heat capacity, } \mathrm{J} /\left(\mathrm{kg}^{\circ} \mathrm{C}\right) \\ \mathrm{D} & \text { Characteristic length, } \mathrm{m}\end{array}$




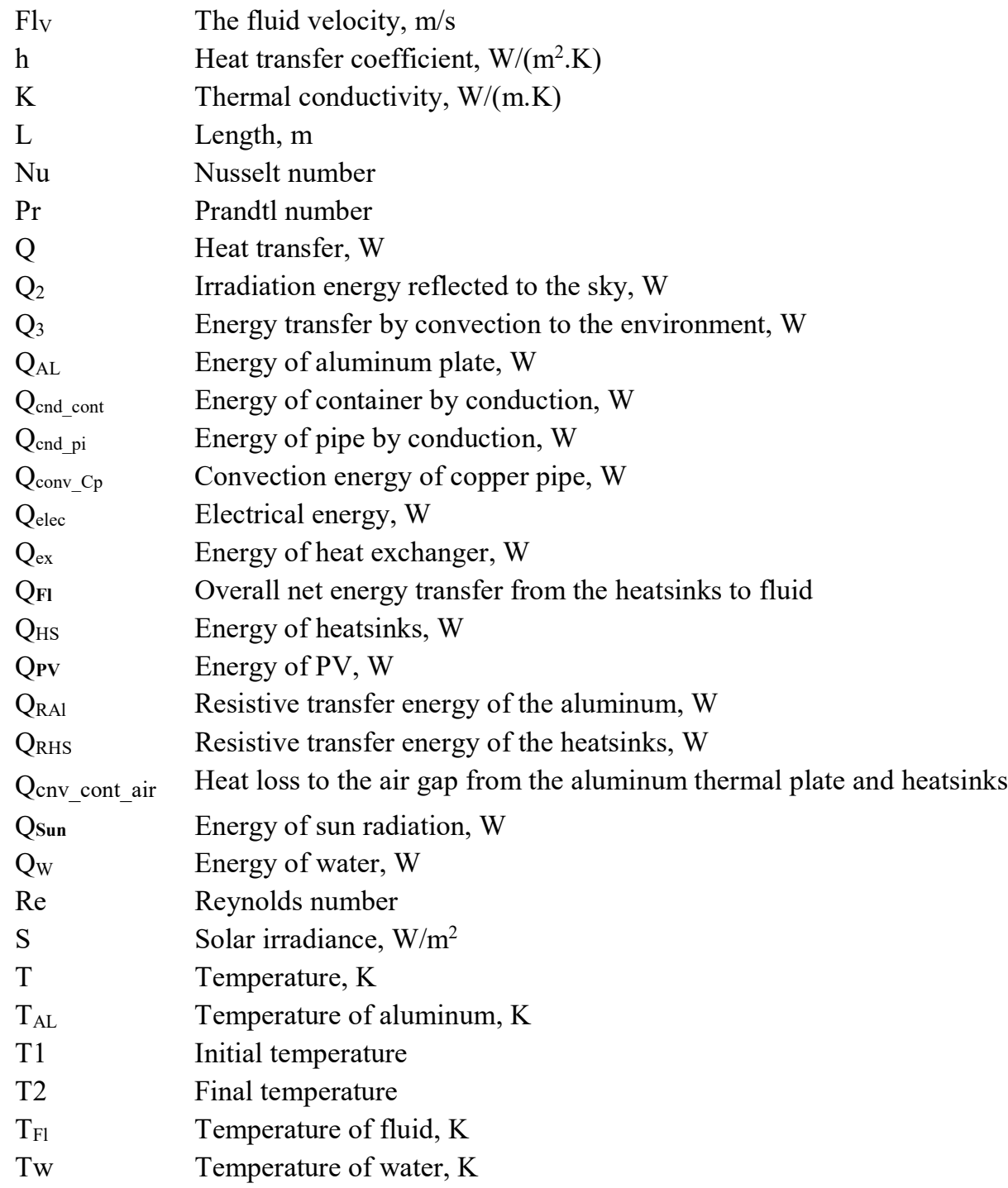

Greek symbols

$\begin{array}{ll}\beta & \text { Volumetric thermal expansion coefficient } \\ \alpha & \text { Absorption coefficient } \\ \mu & \text { The viscosity, } \mathrm{kg} /(\mathrm{s} \cdot \mathrm{m}) \\ \varepsilon & \text { Emissivity } \\ \sigma & \text { Stefan's constant, } 5.67 \times 10^{-8} \mathrm{~W} /\left(\mathrm{m}^{2} \cdot \mathrm{K}^{4}\right) \\ \rho & \text { Density, } \mathrm{kg} / \mathrm{m}^{3} \\ \varepsilon g & \text { Emissivity of glass }\end{array}$

Subscripts

$\begin{array}{ll}\mathrm{Al} & \text { Aluminum thermal plate } \\ \mathrm{HS} & \text { Heatsinks } \\ \mathrm{Fl} & \text { Fluid in the container } \\ \mathrm{w} & \text { Water in the water tank } \\ \mathrm{arc} & \text { Acrylic thermal container } \\ \mathrm{PV} & \text { Photovoltaic panel } \\ \mathrm{amb} & \text { Ambient } \\ \mathrm{Wv} & \text { Wind velocity } \\ \mathrm{Pi} & \text { Rubber pipe } \\ \mathrm{Cp} & \text { Copper pipe }\end{array}$




$\begin{array}{ll}\text { gl } & \text { Glue } \\ \text { conv } & \text { Convection } \\ \text { cnd } & \text { Conduction } \\ \mathrm{g} & \text { Glass } \\ \text { ex } & \text { Heat exchanger } \\ \text { mid } & \text { Middle part of the pipe } \\ \text { in } & \text { Inside the pipe }\end{array}$

\section{REFERENCES}

[1] Owusu P, Asumadu-Sarkodie S. A review of renewable energy sources, sustainability issues and climate change mitigation. Cogent Engineering. 2016; 3(1): 1-14. https://doi.org/10.1080/23311916.2016.11679 90 .

[2] Intergovernmental Panel on Climate Change. Energy supply. In: Climate Change 2007 - Mitigation of Climate Change: Working Group III contribution to the Fourth Assessment Report of the IPCC. Cambridge: Cambridge University Press; 2007. p. 251-322. https://doi.org/10.1017/CBO9780511546013. 008.

[3] Akadiri P, Chinyio E, Olomolaiye P. Design of A Sustainable Building: A Conceptual Framework for Implementing Sustainability in the Building Sector. Buildings. 2012; 2(2): 126-52. http://dx.doi.org/10.3390/buildings2020126.

[4] Nahar A, Hasanuzzaman M, Rahim N, Parvin S. Numerical investigation on the effect of different parameters in enhancing heat transfer performance of photovoltaic thermal systems. Renewable Energy. 2019; 132:284-295. https://doi.org/10.1016/j.renene.2018.08.008.

[5] Hussein A. Applications of nanotechnology to improve the performance of solar collectors - Recent advances and overview. Renewable and Sustainable Energy Reviews. 2016; 62:767-792. https://doi.org/10.1016/j.rser.2016.04.050.

[6] Hussein A. Applications of nanotechnology in renewable energies-A comprehensive overview and understanding. Renewable and Sustainable Energy Reviews. 2015; 42:460-476. https://doi.org/10.1016/j.r ser.2014.10.027.

[7] Chen J, Liu Y. Locally linear embedding: a survey. Artificial Intelligence Review. 2011; 36(1): 29-48. https ://doi.org/10.1007/s10462-010-9200-z.

[8] Computational Fluid Dynamics (CFD) [Internet]. Ifes-koeln.de. 2020 [cited 09 September 2018]. Available from: https://www.ifes-koeln.de/en/services-20-years-project-experience/simulation-analysis/c omputational-fluid-dynamics-cfd.html.

[9] Cooper P. Some factors affecting the absorption of solar radiation in solar stills. Solar Energy. 1972;13(4): 373-381. https://doi.org/10.1016/0038-092X(72)90003-5.

[10] Hilbert S, Hänggi P, Dunkel J. Thermodynamic laws in isolated systems. Physical Review E. $2014 ; 90$ (6). https://doi.org/10.1103/physreve.90.062116.

[11] Lotfi A. Numerical Analysis of Heat Transfer for Cooling of Photovoltaic Cells. PAMM. 2014; 14(1): 501-502. https://doi.org/10.1002/pamm.201410238.

[12] Hammami M, Torretti S, Grimaccia F, Grandi G. Thermal and Performance Analysis of a Photovoltaic Module with an Integrated Energy Storage System. Applied Sciences. 2017; 7(11): 1107. https://doi.org/10.3390/app7111107.

[13] Heat Transfer Enhancement by Finned Heat Sinks with Micro-structured Roughness. Ventola L, Chiavazzo E, Calignano F, Manfredi D, Asinari P. Turin: IOP Publishing; 2014. p. 1-9. https://doi.org/10.1088/17426596/494/1/012009.

[14] Zhou X, Li X, Cheng K, Huai X. Numerical Study of Heat Transfer Enhancement of Nano Liquid-Metal Fluid Forced Convection in Circular Tube. Journal of Heat Transfer. 2018; 140 (8). https://doi.org/10.1115/1.4039685.

[15] Baliga B, Azrak R. Laminar Fully Developed Flow and Heat Transfer in Triangular Plate-Fin Ducts. Journal of Heat Transfer. 1986;108 (1): 24-32. https://doi.org/10.1115/1.3246900.

[16] Sharma A, Cogley A. Numerical Techniques in Radiative Heat Transfer for General, Scattering, PlaneParallel Media. Numerical Heat Transfer. 1982; 5(1): 21-38. https://doi.org/10.1080/10407788208913433.

[17] How Does Heat Affect Solar Panel Efficiencies? [Internet]. CED Greentech. [cited 12 December 2017]. Available from: https://www.cedgreentech.com/article/how-does-heat-affect-solar-panel-efficiencies.

[18] King D, Kratochvil J, Boyson W. Temperature coefficients for PV modules and arrays: measurement methods, difficulties, and results. Twenty Sixth IEEE Photovoltaic Specialists Conference. Anaheim, CA, USA: IEEE; 1997. p. 1183-1186. https://doi.org/10.1109/PVSC.1997.654300. 


\section{APPENDIX}

Table 2. Parameters in the modelling

\begin{tabular}{|c|c|c|c|}
\hline Abbreviation & Definition & value & unit \\
\hline $\mathrm{A}_{\mathrm{Al}}$ & Area of aluminum plate & 0.2485 & $\mathrm{~m}^{2}$ \\
\hline $\mathrm{A}_{\operatorname{arc}}$ & Area of acrylic & 0.2485 & $\mathrm{~m}^{2}$ \\
\hline $\mathrm{A}_{\mathrm{HS}}$ & Area of heatsinks & 0.2485 & $\mathrm{~m}^{2}$ \\
\hline $\mathrm{A}_{\mathrm{TP}}$ & Area of thermal paste & 0.2485 & $\mathrm{~m}^{2}$ \\
\hline $\mathrm{A}_{\mathrm{g}}$ & Area of glass & 0.2485 & $\mathrm{~m}^{2}$ \\
\hline$A_{p v}$ & Area of PV & 0.2485 & $\mathrm{~m}^{2}$ \\
\hline $\mathrm{b}_{\mathrm{Al}}$ & Thickness of aluminum plate & 0.005 & $\mathrm{~m}$ \\
\hline $\mathrm{B}_{\mathrm{TP}}$ & Thickness of thermal paste & 0.001 & $\mathrm{~m}$ \\
\hline $\mathrm{h}_{\text {cont_air }}$ & Thermal conduction of air in container & 0.024 & $\mathrm{~W} /\left(\mathrm{m}^{2} \cdot \mathrm{K}\right)$ \\
\hline $\mathrm{h}_{\mathrm{W}}$ & Thermal conduction of water in Container & 0.6 & $\mathrm{~W} /(\mathrm{m} \cdot \mathrm{K})$ \\
\hline $\mathrm{h}_{\mathrm{amb}}$ & Ambient heat transfer's coefficient & 8.55 & $\mathrm{~W} /\left(\mathrm{m}^{2} . \mathrm{k}\right)$ \\
\hline $\mathrm{K}_{\mathrm{Al}}$ & Thermal conduction of aluminum & 222 & $\mathrm{~W} /(\mathrm{m} . \mathrm{K})$ \\
\hline $\mathrm{K}_{\mathrm{arc}}$ & Conductivity of acrylic & 0.2 & $\mathrm{~W} /(\mathrm{m} \cdot \mathrm{K})$ \\
\hline $\mathrm{K}_{\mathrm{CP} \_ \text {mid }}$ & Thermal conduction of pipe (copper) & 386 & $\mathrm{~W} /(\mathrm{m} . \mathrm{K})$ \\
\hline $\mathrm{K}_{\mathrm{HS}}$ & Conductivity of heatsinks & 222 & $\mathrm{~W} /(\mathrm{m} \cdot \mathrm{K})$ \\
\hline $\mathrm{K}_{\mathrm{TP}}$ & Thermal conduction of thermal paste & 5 & $\mathrm{~W} /(\mathrm{m} . \mathrm{K})$ \\
\hline $\mathrm{K}_{\text {pmid }}$ & Thermal conduction of pipe (nylon) & 0.25 & $\mathrm{~W} /(\mathrm{m} \cdot \mathrm{K})$ \\
\hline $\mathrm{L}$ & Length of nylon pipe & 1 & $\mathrm{~m}$ \\
\hline $\mathrm{L}_{\mathrm{CP}}$ & Length of copper pipe & 2 & $\mathrm{~m}$ \\
\hline $\mathrm{L}_{\mathrm{HS}}$ & Length of heatsinks' fins & 0.047 & $\mathrm{~m}$ \\
\hline $\mathrm{R}_{\mathrm{Al}}$ & Thermal resistance of aluminum & $9.06339 \mathrm{E}-05$ & $\mathrm{~K} / \mathrm{W}$ \\
\hline $\mathrm{r}_{1}$ & Inner diameter nylon tube & 0.01 & $\mathrm{~m}$ \\
\hline $\mathrm{r}_{1-\mathrm{CP}}$ & Inner diameter copper tube & 0.01 & $\mathrm{~m}$ \\
\hline $\mathrm{r}_{2}$ & Outer diameter nylon tube & 0.012 & $\mathrm{~m}$ \\
\hline $\mathrm{r}_{2-\mathrm{CP}}$ & Outer diameter copper tube & 0.012 & $\mathrm{~m}$ \\
\hline $\mathrm{T}_{\mathrm{Al}}$ & Temperature of aluminum plate & 298 & $\mathrm{~K}$ \\
\hline $\mathrm{T}_{\text {arc }}$ & Temperature of acrylic & 298 & $\mathrm{~K}$ \\
\hline $\mathrm{T}_{\text {cont_air }}$ & Temperature of air in container & 298 & $\mathrm{~K}$ \\
\hline $\mathrm{T}_{\mathrm{Fl}}$ & Temperature of fluid & 350 & $\mathrm{~K}$ \\
\hline $\mathrm{T}_{\mathrm{HS}}$ & Temperature of heatsinks & 298 & $\mathrm{~K}$ \\
\hline $\mathrm{T}_{\mathrm{TP}}$ & Temperature of thermal paste & 298 & $\mathrm{~K}$ \\
\hline $\mathrm{T}_{\mathrm{w}}$ & Temperature of water & 298 & $\mathrm{~K}$ \\
\hline $\mathrm{T}_{\mathrm{amb}}$ & Temperature of ambient & 298 & $\mathrm{~K}$ \\
\hline $\mathrm{T}_{\mathrm{g}}$ & Temperature of glass & 298 & $\mathrm{~K}$ \\
\hline $\mathrm{T}_{\mathrm{pv}}$ & Temperature of PV & 298 & $\mathrm{~K}$ \\
\hline $\mathrm{T}_{\mathrm{ref}}$ & Reference Temperature & -- & $\mathrm{K}$ \\
\hline $\mathrm{Wv}$ & Wind speed & 0 & $\mathrm{~m} / \mathrm{s}$ \\
\hline$\alpha_{\mathrm{pv}}$ & Absorption of PV & 0.75 & dimensionless \\
\hline$\beta$ & Volumetric thermal expansion & 0.0034 & $\mathrm{~K}^{-1}$ \\
\hline$\varepsilon_{\mathrm{g}}$ & Emissivity of glass & 0.95 & dimensionless \\
\hline$\eta_{\text {ref }}$ & Reference efficiency & 0.15 & dimensionless \\
\hline$\sigma$ & Stefans-Boltzmann constant & $5.67 \times 10^{-8}$ & $\mathrm{~W} /\left(\mathrm{m}^{2} \cdot \mathrm{K}^{4}\right)$ \\
\hline $\mathrm{h}_{\mathrm{Fl}}$ & Thermal conduction of fluid & 0.6 & $\mathrm{~W} /(\mathrm{m} . \mathrm{K})$ \\
\hline
\end{tabular}

